\title{
TRAÇOS DE UM MAL ESTRANHO: A FICÇÃO PORTUGUESA CONTEMPORÂNEA
}

Lucia Castello Branco

A literatura nāo é inocente e, como culpada, tinha que afinal acabar por confessá-lo.

contundência de Georges Bataille, no prefácio de sua conhecida obra
A Literatura e o $\mathrm{Mal}$, de 1957 , talvez funcione aqui como um pórti-
co para situarmos boa parte da ficção produzida em Portugal nos últimos dez anos. Isso não quer dizer que a literatura portuguesa, no passado, se apresentasse despossuída de culpa, inocente, sem mácula.

Desde as cantigas medievais, em que o escárnio vinha descortinar, na dimensão do horror, a beleza irretocável da donzela e do amor cortês, a suposta inocência da lírica estaria, para sempre, maculada. De lá para cá, de Camões a Pessoa, com ressonâncias inconfundiveis em escritores como Camilo Castello Branco e Eça de Queirós, ou poetas como Cesário Verde, Florbela Espanca e Mário de Sá-Carneiro, as estreitas relações entre a literatura e o mal se fariam ouvir, assinalando, na dimensão de Bataille, que "quanto maior a beleza, maior a mancha".

Entretanto, o texto contemporâneo português trará matizes diferentes para essa articulação entre a literatura e o mal. Não mais marcada por uma noçāo exatamente demoníaca da literatura, como no final do século XIX, a ficçāo portuguesa da contemporaneidade termina finalmente por exibir o malestar que reside na base de qualquer processo de criaçāo, o mal-estar que deriva da subtração entre o mundo que se deseja e o mundo em que se vive, entre o texto idealizado e o texto conseguido, entre a palavra e a coisa, afinal.

Boletim do CESP v. 17, n.21, jan. / dez. 1997 
"A literatura é o essencial ou não é nada. O Mal — uma forma aguda do $\mathrm{Mal}$ - que a literatura expressa, possui para nós (...) o valor soberano", diz Bataille. $O$ que dizer de um texto para o qual nada mais é essencial, nem mesmo a literatura? O que dizer de um texto que, tomado por um tédio de final de século, não mais pelospleen byroniano do passado, mas pela banalização das relações e dos costumes, pela dessacralização da palavra e da imagem, pela disseminação dos afetos e das paixões, ainda assim, assinala, para o leitor, a estreita aliança entre a literatura e o mal?

"A escrita de Maria Gabriela Llansol deixa o pressentimento de um mal estranho: uma doença secreta envolve a imagem que de nós formamos como um todo articulado em faculdades. Desfazendo nós, anulando evidências, o mal despedaça, reparte-nos pela escrita: coisas, idéias, lugares, tudo é escrita, tudo participa da mutação e da permanência da escrita", diz Silvina Rodrigues Lopes a respeito da inquietante estrankeza do texto da escritora portuguesa Maria Gabriela Llansol. E talvez seja dessemal estranho que nos despedaça pela ação da própria escrita que boa parte da fiç̧ão portuguesa da atualidade nos faça sofrer.

Num ensaio de 1929, "O mal-estar na civilização", Freud assinala o quanto o destino do homem está condenado ao mal-estar, já que o próprio processo civilizatório o obriga a abrir mão de satisfações imediatas, buscando adiá-las, sublimá-las, em prol da civilização. Nesse processo, o autor destacará dois elementos fundamentais, que se opõem de maneira frontal ao processo civilizatório: 0 amor $\mathrm{e}$ a mulher.

Segundo Freud, "o amor se coloca em oposição aos interesses da civilização, ou esta ameaça o amor com relaçōes substanciais". Na dialética amorosa, o papel da mulher também se desenvolverá em sentido oposto à civilização: "as mulheres logo se opõem à civilização e demonstram sua influência retardante e coibidora - as mesmas mulheres que, de início, estabeleceram os fundamentos da civilização pelas reivindicações de seu amor (...) O traba- 
lho de civilização tornou-se cada vez mais um assunto masculino (...) Dessa maneira, a mulher se descobre relegada a segundo plano pelas exigências da civilização e adota uma atitude hostil para com ela".

Curiosamente, esses dois elementos — o amor e a mulher - ocuparão um lugar privilegiado nos textos de ficção que aqui tomaremos como exemplares dessa dimensão do mal-estar na literatura portuguesa da última década: Ensaio sobre a cegueira, de José Saramago, A ordem natural das coisas, de António Lobo Antunes, A vida inteira, de Miguel Esteves Cardoso, Catarina ou o sabor da maçãa, de António Alçada Baptista, Ponto pé de flor, de Clara Pinto Correia, A casa da cabeça de cavalo, de Teolinda Gersão, Insânia, de Hélia Correia e Hölder, de Hölderlin, de Maria Gabriela Llansol.

Oito romances, oito autores. Quantas formas do mal? Algumas reiteram que o mal reside na ordem natural das coisas, como na ficção de António Lobo Antunes, outras apontam para o fato de que o mal é decorrente justamente das coisas fora da ordem, como em Ensaio sobre a cegueira, de Saramago. Outras, ainda, fazem o mal tender para a ordem do sobrenatural ou do fantástico, como ocorre na ficção de Hélia Correia e de Teolinda Gersão, ou mais além, para a desordem instaurada pela loucura e pela poesia, como em Hölder, de Hölderlin, de Maria Gabriela Llansol.

E há ainda aqueles que investem no aforisma lacaniano, afirmando que "não há relação sexual", exibindo o eterno desencontro entre o homem e a mulher, como na ficção de António Alçada Baptista, de Clara Pinto Correia e de Miguel Esteves Cardoso. Este último terminaria mesmo por resumir a máxima lacaniana, no título de um de seus livros recentemente publicado: $O$ amor é fodido. E, em todos eles, as figuras do amor e da mulher emolduram o malestar, como a dizer, com Bataille, que "o mal, na medida em que traduz a atraçāo para a morte (...) não é jamais objetivo, mas sempre ambíguo" e que, por isso, "seria inútil dissimular que, no Mal, há sempre o deslize para o pior, que justifica a angústia e o asco".

Boletim do CESP v. 17, 11.21, jan. / dez. 1997 


\section{O mal natural das coisas}

Se podes olhar, vê. Se podes ver, repara.

A epígrafe, extraída do Livro dos Conselhos, abre o livro. E aí o leitor já se depara, antes mesmo que saiba do que vai se passar, com a possibilidade de sua própria cegueira: o olhar, ou, mais que olhar, a visão, são reservados não a qualquer leitor, mas àqueles que podem olhar, que podem ver.

Imaginemos, então, o primeiro paradoxo que nesse livro se instaura: 0 que pode fazer, diante de um texto, um leitor cego? Ou, mais ainda: será possível ler depois de ter os olhos estourados por uma treva branca, como aquela que gradativamente vai tomando os moradores da cidade? O leitor, já de antemão participando da fobia do contágio da cegueira, procura abrir os olhos. E o que vê é um mar de leite que se estende a sua frente: Ensaio sobre a cegueira, de José Saramago.

Assim se inicia o romance: rasgando, sem pedir licença, os olhos do próprio leitor. Assim se inicia o mal-estar - do leitor, da leitura. É possível ler o branco sobre o branco? As letras, esses pequenos caracteres que se distinguem da página exatamente por sua cor negra, que função podem ter, depois de liquefeitas nesse mar de leite?

Talvez seja daí que se inicie a própria liquefação da narrativa: pouca ação, pouco movimento, apenas a cegueira gradativa e lenta a ocupar a cena. O que se opera, de maneira cabal, nesse livro de Saramago, é o que Derrida chamou de disseminação: a cegueira está em toda a parte.

Entretanto, é preciso que, em meio a esse mar de leite, alguém possa olhar, alguém possa ver para o leitor. E quem vê é a mulher: a mulher do médico. Ambos acabam por ser recolhidos num manicômio vazio, juntamente como os demais moradores da cidade que, aos poucos, vão sendo acometidos pelo "mal-branco". O médico, porque de fato havia sido contagiado pelo mal; a mulher, por um estranho sentido de fidelidade ao marido (ou de fidelida- 
de à cegueira?):

Vou pedir-lhes que te levem para casa, dizer-lhes que os enganaste para ficar comigo, Não valc a pena de lá não te ouvem, e ainda que te ouvissem nāo fariam caso, Mas tu vês, Por enquanto, o mais certo é cegar também um dia destes, ou daqui a um minuto, Vai-te embora, por favor, Não insistas, aliás aposto que os soldados nem me deixariam por um pé nos degraus, Nāo te posso obrigar, Pois não, meu amor, nāo podes, fico para te ajudar, e aos outros que aí venham, mas não lhes diga que eu vejo, Quais outros, Com certeza não crês que vamos ser os únicos, Isto é uma loucura, Deve de ser, estamos num manicómio.

Assim se desenvolve a narrativa: filtrada pelo olhar da mulher, a única que ali vê, contaminada pelo temor da mulher de que a qualquer momento também ela fosse acometida pelo "mal-branco", mas sobretudo contaminada, a própria narrativa, por uma inquietante inversão que ali se opera: aquela que vê não pode ser vista pelos demais.

Essa inversão, aparentemente banal, traduz o movimento operado pela ficção de Saramago: ali, são os objetos que vêem o sujeito e não o sujeito que os vê. Ou, nas palavras de um dos cegos: "Há mil razões para que o cérebro humano se feche, só estendeu as mãos até tocar o vidro, sabia que a sua imagem estava ali a olhá-lo, a imagem via-o a ele, ele não via a imagem".

Nisso constitui a cegueira: o objeto vê, enquanto ao sujeito, por sua vez, só resta ser visto e nada mais. E é também esta a posição em que o leitor é colocado: só lhe resta "ver" o que é visto pela mulher, o que também termina por trazer à tona a priorizaçāo das imagens (dos objetos), que tudo vêem, e da cegueira do leitor. "A imagem via-o a ele, ele não via a imagem".

Nesse mar de leite, que ora se assemelha a um louco agregamento, como em "O alienista", de Machado de Assis, ora se aproxima, em seu descritivismo escatológico, das narrativas naturalistas do final do século XIX, somos todos cegos. Resta, inquietante, a questão: ainda somos sujeitos?

Ao final do romance, após todo tipo de humilhaçāo e de miséria por que passaram, após a gradativa animalização dos gestos e dos costumes, após a 
fome, a sede, a doença e o desamparo, acompanhados de um considerável aprimoramento da sensibilidade e do tato, aqueles poucos que escaparam à morte vão, subitamente, recobrando a visão, para concluírem, de maneira um tanto explícita: "Por que foi que cegámos, Não sei, talvez um dia se chegue a conhecer a razão, Queres que te diga o que penso, Diz, Penso que não cegámos penso que estamos cegos, Cegos que vêem, Cegos que, vendo, não vêem."

E a mulher? "A mulher do médico levantou-se e foi à janela. Olhou para baixo, para a rua coberta de lixo, para as pessoas que gritavam e cantavam. Depois levantou a cabeça para o céu e viu-o todo branco. Chegou a minha vez, pensou. O medo súbito fê-la baixar os olhos. A cidade ainda ali estava."

Acometida, ao final, pelo branco da cegueira — ou pelo branco da visão - , a mulher abandona o leitor a sua própria cegueira de cego que vê, de cego que, vendo, não vê.

Estamos, é claro, diante de um texto político, como, aliás, toda a ficção de Saramago. Mas estamos diante de um texto - em ensaio, pode-se dizer, um ensaio sobre a cegueira - em que as questões da ética e do mal-estar se colocam de maneira evidente.

"São a fome e o amor que movem o mundo", dizia o poeta-filósofo Schiller, citado por Freud em "O mal-estar na civilização". Ao que Freud acrescentaria, com a contundência de sua voz cujos ecos podem se ouvir, analogamente, ao fim dessa narrativa de Saramago:

Os homens adquiriram sobre as forças da natureza um tal controle, que, com sua ajuda, não teriam dificuldades em se exterminarem uns aos outros, até o último homem. Sabem disso, c é daí que provém grande parte de sua atual inquictação, de sua infelicidade e de sua ansiedade. Agora só nos resta esperar que o outro dos dois 'Poderes Celestes', o eterno Eros. desdobre suas forças para se arirmar na luta com seu nāo menos imortal adversário. Mas quem pode prever com que sucesso e com que resultado?

Em busca, talvez, de uma resposta, a mulher olha para o céu. Mas o que vê é apenas um mar de leite.

Traf̧os de Um Mal Estranho... Lucia Castello Branco- Págs. 25-43 
Numa atmosfera que antecipa o que ocorre nesse romance de Saramago, o mal-estar também se encena na narrativa de António Lobo Antunes, muito propriamente intitulada como $A$ ordem natural das coisas. Observe-se esta descrição da cidade de Lisboa:

Lisboa, meu amor, cram missas radiofônicas, altarzinhos de Santo Antônio, mendigos c gaitas de cegos nas esquinas, porque nunca encontrei tantos cegos como nessa época penosa, cegos encostados aos prédios, cegos de concertina as costas tateando passcios fora, cegos trágicos à saída dos lausperenes, cegos fadistas acompanhados por espertalhões de patilhas que recebiam as esmolas, cegos ameaçadores que vendiam bugigangas no adro, cegos orgulhosos, de queixo altivo, nos cruzamentos das ruas, mulheres cegas, com filhos cegos que nāo choravam nunca ao colo, cegos bêbados as curvetas entre os palmitos das tabernas, cegos que se suspendiam no ar, como anjos (...) c eu a perguntar à minha tia $O$ que $\varepsilon$ feito dos meus pais? e cla, sem interromper o crochê, a revirar os olhos, cegos a tocarem-se ao portāo ou a vagueraem na relva, enganados na morada, e nesse momento, querida, cegosescutei pela primeira vez, fazendo vibrar os cálices, as folhas das plantas e o arbusto do meu sangue, cegos um ruído de passos no andar de cima.

Mas nāo é exatamente como uma alegoria sobre a cegueira dos homens que a narrativa de Lobo Antunes se desenvolve. Trata-se, antes, de uma ficção sobre as pequenas misérias humanas, privilegiando aí as doenças do corpo e do coração, a morte, o mal-estar, envolvidos, sempre, pelo cenário decadente de Lisboa, a "cidade submersa", e seus arredores:

Do mesmo modo que hoje a tua doença, Iolanda, me surpreende, com as suas tremuras, os seus desmaios, seus suores, os seus cheiros de pétalas pisadas e a sua subterrânea $e$ intensa comunicação com a morte, que te envelhece por dentro como se os 6́rgāos, o coração, o estómago, o fígado, antiquíssimos e apodrecidos como os dois heróis nas criptas, se decompusessem sob a vitoriosa juventude da pele, também na época da minha infância, na Ericeira primeiro, c na calçada do Tojal depois, os meus pais constitúam um absoluto mistério para mim. 
Constituído de cinco blocos que se entrecruzam - "Doces odores, doces mortos", "Os argonautas", "A viagem à China", "A vida contigo", "A representação alucinatória do desejo"-, o livro de Lobo Antunes desenvolve-se em grandes monólogos das personagens que, ao reconstruírem sua memória individual, acabam por construir, aos pedaços, uma certa memória de Lisboa. Mas, assim como a memória está irremediavelmente imersa no branco do esquecimento, da lacuna, Lisboa permanece submersa em seu mar de trevas:

De forma que comecei a caminhar para a Venda Nova, alheia às pessoas que se cruzavam comigo e se voltavam para me fitar, a valsa perdeu-se atrás de mim, um bêbado de smoking e chapéu alto resmungou uma frase que não entendi, e ao atingir os prédios da Amadora enegrecera de tal modo que alé a minha sombra se sumiu. Porém havia janelas iluminadas e a chuvinha de outubro ascendendo no escuro. As trevas impediam-me de distinguir os barcos, impediam-me de distinguir o salva-vidas, as trainciras, as grazinas, as dunas, a ponte romana e a esplanada de Tavira, impediam-me as arvéolas nos penedos, os cestos de pescado, o sol nas ondas e os caranguejos da vazante, impediam-me de distinguir o meu irmão Jorge sorrindo à minha espera, mas não valia a pena chamá-lo por já me achar perto dele, por me achar perto do mar.

O mar, as imagens, as pessoas, estão lá. Mas permanecem submersos nas trevas, como a cidade. E, apesar da constante aferição da memória e dos afetos, o outro e a cidade permanecem desconhecidos para o sujeito: "Mesmo hoje, em que passeio Loreto fora até ao elevador da Bica e vejo a cidade descer ao sol para os armazéns da Ribeira, mesmo hoje, dizia, não conheço Lisboa".

A cidade é submersa, a memória é submersa, o afeto é submerso, a vida é submersa. Nisso reside a ordem natural das coisas. E, nessa ordem, o mal-estar de um sujeito fraturado, de um sujeito que não se reconhece nas imagens que o interpelam e que lhe causam dor:

- O que tens tu, Alfredo? 
- Dói-me a barriga, pai

por não poder explicar-lhe que é a noite que me dói, e o meu tio para o meu pai, irônico,

- Achas mesmo que está a chover, Teodoro?

Em meio a essa atmosfera em que impera o mal-estar, o amor e a mulher surgem, também aqui, como elementos privilegiados, que assinalam o impossível do sujeito. Seja no primeiro bloco, escrito como uma carta de amor para Iolanda, diabética, adormecida, enquanto seu companheiro, trinta e um anos mais velho, relembra sua infância sob efeito do Valium; seja no último bloco, narrado por uma mulher à beira da morte, acometida por um câncer e pela nostalgia de um mar em trevas, um mar que ela julga nāo existir, porque nunca chegou a vê-lo, a mulher e o amor constituem-se em elementos detonadores do desejo - ou da "representação alucinatória do desejo"-e, portanto, do mal-estar que envolve toda a narrativa.

$\mathrm{E}$, nos dois romances, tanto no de Saramago quanto no de Lobo Antunes, a cegueira e as pequenas misérias são tomadas como um mal natural, um mal da ordem natural das coisas, já que, hoje, as coisas fora da ordem, tāo longe de assinalarem o "desconcerto do mundo", como observava Camões há quinhentos anos, parecem ter se colado ao corpo do homem, à alma do homem, como uma segunda pele.

\section{O mal radical da escrita}

De maneira análoga, mas apostando talvez em outra vertente do mal aquela que assinala a dimensão sobrenatural, estranha, ou mesmo louca das coisas c dos seres - desenvolvem-se as narrativas de Hélia Correia, Teolinda Gersão e Maria Gabriela Llansol.

Frascisco Amor julgara estar armado para o final do mundo que iria acontecer no termo do milênio. Pelo pai, que os ouvira do avó, conhecia os sinais. Em certos casos, poderiam inferir-se pelos textos da Bíblia. Noutros, estavam na fala dos antigos. Ele era, de algum modo, um privilegiado, costumava pensar. Poucos sabiam já das profecias, poucos

Boletim do CESP v. 17, n.21, jan. / dez. 1997 
tinham chegado até ali, para verem cumprir-se o seu terror. Não começava tudo de repente, oh, não. Vinha-se há muito preparando, ano após ano. sem visíveis sobressaltos, exactamente como um ser humano leva o seu tempo a desgastar-se e a morrer. Mesmo em momentos de maior doença, quando matérias invisíveis se soltavam pelas frestas de grandes contentores, pondo nos ares a corrosāo de um ácido, mesmo então, logo após a primeira cstranheza, tornavam as pessoas à rotina sem que pudesse denotar-se nos seus gestos qualquer enervamento adicional. Adaptavase a gente a tudo, até, quem sabe, ao próprio medo da exterminação.

Esta abertura do romance Insânia, de Hélia Correia, já nos prepara para a atmosfera sobrenatural que circundará toda a narrativa. A partir da chegada da menina Natalina à Levada, a cidade vai sendo, aos poucos, ocupada por um mal estranho: "deixara, por exemplo, de existir Primavera. Os meses alternavam entre grandes chuvadas e violento calor, e a floração já não escolhia altura (...) O ar, em vez de gás ou de micróbios, andava saturado de projécteis. E o vento transportava, sem fronteiras, aquela nova cólera de Deus."

Aos poucos, os habitantes de Levada vão atribuindo a ocorrência de estranhos acontecimentos à presença de Natalina, "exemplo da errância dos homens: pouco mais do que um bicho, talvez filha de comércio carnal com o demónio". E a menina, que jamais abre a boca, que não responde às perguntas que lhe fazem, que não esclarece o mistério de sua origem, de sua existência, atravessa a cidade como signo dessa inquietante estranheza que se dissemina pelos ares.

Curiosamente, nesse romance de Hélia Correia, a insânia reside exatamente no que é mais próximo, mais familiar - a criança - e que retorna como estranho, como assustador. Eé exatamente na dimensão dessa familiaridade que se dá o horror: os grupos de pessoas vão perdendo a coesão, a história vai perdendo a coesão, as palavras vão perdendo o poder de revelar, de contar a história.

"Poderia pensar-se que a menina não tinha um interior, que não passava da ligeira escorrência de uma tinta". Assim como a narrativa de Hélia Correia que, aos poucos, vai se liquefazendo, como a escorrência de uma tinta: ao final, mais da metade da população da aldeia desaparecera "como se não 
fosse mais do que um pó, tão fácil de soprar. E o que resta são as palavras de Sandrinha, também elas inconsistentes, insuficientes para conter uma história inconsistente, absurda:

\section{Conta Sandrinha.}

Mas, se repararem, muito tivemos de arranjar sem ela.

De forma que lhe damos voz, pois sim, porém com alguma reserva de critérios. Omitiremos o que nos parece excessivo tom, sobranceria do autor. Porque ela começou a ser ouvida c não mais quis parar, por muito inútil que, passado algum tempo, se tornasse, já que falava sobre sentimentos quando eram factos o que the pediam. E de pouco valia o testemunho de tudo o que ocorrera na Levada, c cra...

O que era?

Perguntava Sandrinha, interrompendo-se.

O que era?

Devolviam, num eco, os salvadores.

E, também nessa narrativa, esse mal que se atribui à ação do demônio é associado à mulher e ao amor: são as levadeiras que, em sua caminhada, parecem ter o demônio a "trocar-lhes as voltas", é a menina quem parece dizimar tudo a sua volta, é a atração pelo rosto da criança que enlouquece o coraçāo das pessoas:

Pegava, assim, num fio capaz de interligar os estranhos sucessos da Levada. Chuvas, ventos, loucura, fé, cegueira, māes indiferentes, frutas ocas, casas mortas, a rede social desfeita em pó, a ilusāo dos olhos, dados a crros próprios dos olhos animais a quem Deus rāo concede a discriminaçāo - que era isso se näo o demo sobre a terra? E que coisa endoidara os corações, para que, $\mathrm{em}$ vez de pulsarem com regularidade, se pusessem a andar à roda do seu centro, engolidos num vórtice que a seguir sugaria a alma e a sensatez - que coisa era, se nāo o rosto da criança?

Boletim do CESP v. 17, n.21, jan. / dez, 1997 
Insiste neste romance, como no de Saramago, o tema da cegueira, ou da "ilusão dos olhos". Mas, diferentemente do que ocorre em Ensaio sobre a cegueira, nāo há agora qualquer redenção, qualquer moral que possa dar um sentido àquilo tudo, pois que tudo se perde na poeira, na inconsistência da tinta que escorre sobre a página.

Cabem aqui, então, as palavras de Silvina Rodrigues Lopes acerca do texto de Llansol: o mal estranho de que essas narrativas sofrem reduz-se ao "mal da escrita", que nos reparte, nos despedaça, "desfazendo nós, anulando evidências", fazendo com que tudo participe da mutação, da permanência e da absurda inconsistência da própria escrita.

Numa dicção semelhante à de Insânia constrói-se o romance $A$ casa da cabeça de cavalo, de Teolinda Gersão. Ali também encenam-se as questões da loucura, do feminino e da inconsistência dos seres e dos acontecimentos, cercados, não pelos limites de uma aldeia, mas de uma casa "quebradiça e vã", dada a estranhos acessos de loucura: "Eram talvez os saltos do cavalo que davam origem às convulsões da Casa, a que alguns preferiam chamar acessos de loucura".

Esta casa, habitada por estranhos mortos, é aos poucos também dissolvida na inconsistência de sua própria loucura: "Mas tudo isso eram desculpas. A verdade é que endoideciam. Como se andassem no ar grãos de loucura, misturados no pólen e no vento. Ou então era o ar que embriagava." E aqui, também, as portadoras privilegiadas desse estranho mal são as mulheres:

Durante muitos anos, foi assim que fez. Com um sentimento de culpa, como se esse ritual fosse, de algum modo, proibido. Porque ela tinha certeza de que o diabo tomava parte nos seus feitiços (...) Porque tudo isso lhe era familiar e antigo, embora o ouvisse pela primeira vez. E ficava a soar dentro dela, como um búzio. Se quisesse, também podia voar, sentia debruçando-se mais no parapeito. Bastava entrar no mal com mais força. Enlouquecer. Abrir à noite a janela e dizer ao demónio: Vem, vem. 
Analogamente ao romance de Hélia Correia, as coisas e os seres nessa narrativa são assolados pelo desaparecimento, pela inconsistência e pela dissolução. Por fim, até mesmo a casa termina por desaparecer, assim como as palavras são varridas das páginas, restando apenas o branco do papel:

um resto de memória que se ia gastando, como uma vela de cera, e quando acabasse também eles chegariam ao fim e nāo haveria mais nada

- um caderno deixado sobre a mesa, para os que viessem depois, palavras escritas, como um risco no tempo - mas o vento varria as palavras c todo o papel ficava em branco então apagaram-se as luzes, um relincho atroou os ares, algo passou por cles, vertiginosamente, tocou-lhes no rosto como uma labareda, e a Casa desapareceu.

Enveredando também por essa vertente do mal estranho, em que tudo participa da paisagem da escrita, o texto de Maria Gabriela Llansol, Hölder, de Hölderlin, já não partilha exatamente da dicção fantástica dos romances de Hélia Correia e Teolinda Gersão, mas habita um outro universo, o universo do outro por excelência. Já não se trata ali de escrever sobre a loucura, mas de permitir que a loucura fale, em sua alteridade radical.

O livro, se pudéssemos de alguma maneira resumi-lo, poderia ser entendido como a história da gênese da poesia e da loucura do poeta alemão Hölderlin, como a história da ocupação da casa e da mente de Hölderlin pela escrita que, a sua volta, não cessa de escrever:

Hölderlin brincava ali, saltando; ia-se perdendo na sala; via-se deslizar com cle um lugar sem criaturas humanas.

Myriam pensou para Joshua: 'perder-se

no outro perdido

é a experiência que cstá a ter'. Tinha nas mãos

uma porção de excremento humano, que tentava moldar numa superficie de poema; mas a angústia, de modo imerecido, fazia-o saber que a loucura era a mente estar com o poema, c o corpo ausente. 
Como se vê, trata-se também de uma história de perdas, desaparecimentos, inconsistências: "Perder-se no outro perdido é a experiência que está a ter". Mas aqui já não se trata exatamente de uma perda de referência como se dá na cegueira no romance de Saramago ou na disseminação nos romances de Hélia Correia ou Teolinda Gersão - , pois que a referência de início já não se oferece ao leitor. Trata-se, antes, da inconsistência das próprias letras, dos nomes, da linguagem e da inadequação fundamental das palavras às coisas:

Via-se nitidamente envolvido pelas letras do seu nome, e toda a paciência que havia de esgotar na sua vida fixara-se nesse sol poenta - no horizonte; com a adoraçāo - subitamente - subiu-lhe aos lábios a Paixão: louco, e com paciência, dizia a areia caindo com cor da clépsidra das suas mãos (...)

Em meio a esse mal da perda, ou a esse mal da loucura, a mulher e o amor ocupam também lugar privilegiado —é por amor a Diotima que Hölderlin se perdeu: "Diz-me, Hölderlin, a tua razão de partir não foi o amor?"

Ao leitor, só resta também perder-se encarcerado nos limites dessa narrativa "hermeticamente fechada", deixando-se também contaminar por esse mal da escrita que não redime, não consola, não transforma nenhuma lama em pássaro:

A excitação sexual foi-se marcando em todos, em torno do pobre tonto. Nenhuma lama se transformara $\mathrm{em}$ pássaro. Nessa situaçāo de descjo sensual profundo, Giordano Bruno acabara de entrar. Teria dito o que é escabroso no amor é que não tem anel; mas nada disse, nos seus pulmões o ar parecia penetrar por meio de uma bomba e todas as outras imagens haviam sido, longe, hermeticamente fechadas. Até hoje.

\section{Do mal ao pior}

Quando chegamos finalmente no aforisma lacaniano que diz que "não há relação sexual", terminamos por deslizar, como observa Bataille, para o 
pior: E esse universo é, comumente, habitado pela angústia e pelo asco.

Ainda não é esse o tom dado por Clara Pinto Correia a Ponto pé de flor, embora esse romance já explore com detalhes a impossibilidade do encontro entre o homem e a mulher. Dividido em fragmentos intitulados com nomes de mulheres - as amigas da protagonista - e introduzidos por epígrafes recolhidas dos Salmos, Ponto pé de flor focalizará os três ou quatro dias de agonia de uma mulher que acabara de romper um relacionamento amoroso.

Obviamente, trata-se aqui do mal do amor, ou do mal-estar do amor. Mas, ao lado da impossibilidade do encontro amoroso, uma possibilidade se assinala: a do encontro não menos amoroso - a amizade - entre as mulheres. Formando uma espécie de liga feminina — um bordado, em ponto pé de flor -, essas mulheres vāo tagarelar, ao longo da narrativa, exibindo, sem pudores, suas pequenas misérias, suas angústias, sua frivolidade aparente $e$, sobretudo, seu mal-estar diante desse mundo dos homens:

-Dói-te muito? - perguntou ela.

- Dói-me cudo - disse eu.

Quando saíssemos dali a Catarina e o homem que viera com ela no comboio iam meter-se no carro velho da Joana, que estava parado desde a véspera em frente da estação(...)

Depois a Catarina e o ToPê dela estariam já muito longe, e eu não teria nada, nada de meu, a não ser um cão pequenino adormecido dentro de um cabaz de vime.

Ou, como traduz a epígrafe recolhida dos Salmos:

Rodeia-me um bando de homens maus como uma matilha de cães que aperta o cerco. Atacam-me as mãos e os pés.

Os meus inimigos vigiam-me.

Disputam a minha roupa

e dividem-na entre si. 
Entretanto, a dicção desse romance, embora toda ela pontuada pelo desencontro e pelo mal-estar, não se deixa contaminar ainda pelo pior: a angústia e o asco parecem se manter à distância, deslocados por uma ironia aparentemente casual, aparentemente superficial.

Mas também aqui - e de maneira contundente - são as mulheres e o amor os elementos detonadores do mal, embora essa narrativa aposte num certo poder de sobrevivência das mulheres que, unidas por uma ética feminina, enfrentam, com sabedoria e coragem, os desastres causados pelas afecçōes amorosas.

Disso parecem saber alguns homens. Ou, em outras palavras, é desse saber que de alguma forma nos falam António Alçada Baptista e Miguel Esteves Cardoso.

O primeiro, em Catarina ou o sabor da maçã, situa o mal do amor exata e explicitamente nas mãos da mulher: é Catarina quem detém o sabor da maçã, é Catarina quem oferece ao protagonista a maçã e quem lhe proíbe, subitamente, o fruto. Por isso, Catarina se relaciona tão intimamente com o mal que o fascina:

Digo é que acredito que existe o espírito do mal, que existe o demoníaco mas que é hoje diferente a maneira como se manifesta e como a gente comunica com ele. Há o demoníaco e há a capacidade das pessoas se fascinarem com o mal(...) A minha preocupação com Catarina estava, naquele momento, na especial propensão que ela tinha para ser atraída pclos abismos.

Na dimensão do encontro em que o protagonista, a princípio, acredita ("É pena que seja tão difícil às pessoas habituarem-se interiormente a viver um enamoramento, que é, sobretudo, um estado de verdade e de paz"), e do desencontro com que, por fim, ele é obrigado a se deparar, o texto de Alçada Baptista mergulha, definitivamente, no pior:

Mas a boca não tinha um dente e o corpo estava sujo. O cabelo era um ninho que não via água nem pente nem sabão há muito tempo. Agora sinto que, por cstas razōes tão mesquinhas, a Catarina perdeu_um encontro 
que talvez a ajudasse a dar outro rumo à sua vida.

E, nesse universo, o que resta é a angústia e o asco, como observa Bataille.

Numa mesma direção, desenvolve-se o romance $A$ vida inteira, de Miguel Esteves Cardoso. Narrado por uma alma (uma alma feminina, pode-se dizer) que acompanha de perto o corpo e a trajetória de uma mulher - Eva - A vida inteira pode ser resumido como a história dos encontros (e desencontros) de Eva com os homens, ou como a história do mal-estar sexual e da afecçāo amorosa:

O destino dispenso. Mas do caminho nāo desisto. O meu caminho é este. Nunca deveria ter nascido. A ninguém trouxe alegria - só amor. Espalheio sem querer. Foco infeccioso.

A narrativa pode ser reduzida a isso: o sexo e seu mal-estar, as masturbações de Eva e seu mal-estar, o amor infeccioso de Eva e seu malestar. Afinal, como já havia assinalado o autor em seu livro anterior, "o amor é fodido".

Essa frase, a princípio absurdamente melancólica para pontuar um romance em que a dicçāo priorizada é a da ironia e a da superficialidade das relações, pode aqui ser lida em dupla direção: o amor é fracassado, ou o amor reduz-se ao sexo. Aliás, essa segunda leitura é reiterada durante a narrativa, quando se diz: "Porque, quando as pessoas se amam, fodem de verdade".

Para além dessa verdade, há sempre o pior. E o pior, que esbarra na angústia, no asco (e, muitas vezes, no tédio), vem sempre a assinalar que "não há relação sexual". Por isso é impossível que a vida seja inteira, porque não há inteiros, porque o sujeito é sempre fragmentado, sempre dividido por essa verdade inquestionável:

'Nāo podes ficar a vida intcira na cama', dizo o irmāo, todo prático. Eva já gosta delc também. A vida intcira. Intcira como? Cheja? Completa? Una? Como é que se pode falar nestes termos?

Boletin do CESP ห. 17, 1.21, jan. / dez. 1997 
A vida não é inteira, o sujeito não é inteiro e a literatura não é inocente. E, como culpada, tinha que afinal acabar por confessá-lo.

Nesses oito romances aqui abordados, a literatura confessa. Confessa que, de uma maneira ou de outra, as palavras sempre estiveram pactuadas com o mal. Seja no que sai pela boca do homem, seja no que se cala, a literatura, nunca inocente, há de nos repartir, dissolvendo, como uma doença secreta, a imagem que um dia de nós formamos como um todo articulado em faculdades.

\section{RESUMO}

Análise de textos da ficção portuguesa da contemporaneidade (1980/1990), a partir dos conceitos de mal, de Georges Bataille, e de mal-estar, de Freud. Pretende-se demonstrar que a literatura contemporânea afasta-se radicalmente de uma certa noçāo de "bem supremo" que as belas-letras reforçam, ao ser atravessada, na atualidade, pelas forças do "mal da língua".

\section{RÉSUMÉ}

Analyse de textes de la fiction portugaise contemporaine (1980/1990), d'après les concepts de mal, de Georges Bataille, et de malaise, de Freud. On veux démontrer que la litérature contemporaine se détache radicalement d'une cerıaine notion de "bien supreme", renforcée par les belles-lettres, au moment òu elle est traversée, aujourd'hui, par les forces du "mal de la langue".

\section{BIBLIOGRAFIA}

\section{Textos ficcionais}

ANTUNES, António Lobo. A ordem natural das coisas. Rio de Janeiro: Rocco, 1996.

BAPTISTA, António Alçada. Catarina ou o sabor da maçā. Lisboa: Presença, 1988.

CARDOSO, Miguel Esteves. A vida inteira. Lisboa: Assírio \& Alvim, 1995.

CORREIA. Clara Pinto. Ponto pé de flor. Lisboa: Dom Quixote, 1990. 
CORREIA, Hélia. Insânia. Lisboa: Relógio D’Água, 1996.

GERSĀO, Tcolinda. A casa da cabeça de cavalo. Lisboa: Dom Quixote, 1995.

LLANSOL, Maria Gabriela. Hölder, de Hölderlin. Sintra: Colares Editora, 1995.

SARAMAGO, José. Ensaio sobre a cegueira. São Paulo: Companhia das Letras, 1996.

\section{Textos teóricos}

BATAILLE, Geoges. La literatura y el mal. Madrid: Taurus, 1981.

FREUD, Sigmund. O mal-estar na civilização. In: . Edição standard brasileira das obras psicologicas completas de Sigmmind Fretud. v. 21. Rio de Janciro: Imago, 1974. P. 73-171.

LOPES. Silvina Rodrigues. Teoria da des-possessão(ensaio sobre textos de Maria Gabriela Llansol). Lisboa: Black Son, 1988. 